\title{
Telechelic polyisobutylene with unsaturated end groups and with anhydride end groups
}

\author{
E. Walch and R. J. Gaymans* \\ Department of Polymer Technology, Twente University of Technology, PO Box 217, \\ 7500 AE Enschede, The Netherlands \\ (Received 2 June 1992; revised 1 August 1993)
}

\begin{abstract}
Anhydride terminated polyisobutylene (PIB) oligomers were synthesized in a one- or two-step process from chlorine terminated oligomers. In the one-step process, chlorine functional oligomers were just heated in the presence of maleic anhydride (MA) for $12 \mathrm{~h}$ at $190^{\circ} \mathrm{C}$ without a catalyst. In the two-step process, the chlorine end functional groups were first converted by selective dehydrochlorination to isopropenylpolyisobutylene end groups with $\mathrm{t}-\mathrm{BuOK}$ in refluxing tetrahydrofuran during $16 \mathrm{~h}$. In a second step, MA was coupled to the PIB with unsaturated end groups by reacting the oligomer with $\mathrm{MA}$ for $12 \mathrm{~h}$ at $190^{\circ} \mathrm{C}$ These reactions could be followed by i.r. and n.m.r. The PIB-MA obtained had a functionality between $30 \%$ and $100 \%$. In order to study the formation of amine functionalities, the PIB-MA was reacted with diamines. The coupling gave an imide bonding.
\end{abstract}

(Keywords: telechelic; polyisobutylene; end group modification)

\section{INTRODUCTION}

One interesting class of polymers is the segmented block copolymers. Some of these polymers have characteristics of thermoplastic elastomers (TPEs). In these TPEs, one segment is amorphous and has a low glass transition temperature $\left(T_{\mathrm{g}}\right)$ while the other can crystallize and has a high melting temperature. Polyethers, with low thermal and oxidative stabilities, are mainly used for the low $T_{g}$ segment in TPEs.

One segment that has the potential to combine this low $T_{\mathrm{g}}$ with good stability is polyisobutylene (PIB). In order to synthesize block copolymers containing PIB, end functional PIB oligomers (telechelics) have to be used. At present, these materials are not available with suitable end groups. Linking of the segments is normally accomplished by a condensation reaction. Therefore, the PIB should be functionalized with end groups that are reactive in a polycondensation reaction. To obtain a linear, high molecular weight polymer, these segments should be exactly bifunctional.

With anionic polymerization, it is possible to obtain well-defined end groups. This is also true for some cationic polymerizations ${ }^{1}$. With the living PIB synthesis chlorine end groups are nearly always obtained. Termination of living PIB with $\mathrm{EtN}_{3}$, pyridine and methanol gave solely chlorine end groups ${ }^{2}$. The same occurs with other nucleophiles like esters, anhydrides, ethers, ketones, dimethylsulfoxide and $N, N$-dimethylacetamide $^{3}$. There are only a few exceptions. It has been shown that it is possible to link anisole to the living end ${ }^{4}$. Also, allyl end groups were introduced in one step by terminating with allyltrimethylsilane ${ }^{3}$ or an allylstannate ${ }^{5}$.

*To whom correspondence should be addressed

0032-3861/94/08/1774-05

(C) 1994 Butterworth-Heinemann Ltd
The chlorine end group of PIB-Cl can be converted to obtain functional groups ${ }^{6,7}$ suitable for further polymerization. By elimination of $\mathrm{HCl}$ from the chain end, a' PIB oligomer with an unsaturated end group is obtained (PIB-U). The elimination is carried out by heating the PIB-Cl and two kinds of unsaturated groups are formed: one with a double bond inside the polymer chain at a 2,3-position ('endo') and one with the double bond outside the chain at the 1,2-position ('exo'). The exo form is preferred because it has a higher reactivity ${ }^{8}$. It can be obtained quantitatively by abstracting the $\mathrm{HCl}$ with a sterically hindered base such as $\mathrm{t}-\mathrm{BuOK}^{9,10}$ or even with EtONa ${ }^{11}$.<smiles>[R]CC(C)(C)Cl</smiles><smiles>CCC</smiles><smiles>[R]CC(=C)C(C)=C(C)C</smiles>

The exo double bond can be used to add a variety of compounds to the chain end ${ }^{12}$. One of the possibilities is the addition of an unsaturated anhydride group ${ }^{13-15}$ by an ene reaction. With this type of reaction only one monomer is added. This anhydride group will give a telechelic that is reactive towards alcohol and amine groups. The addition of acrylic acids is not favourable as their rate of reaction of an ene type is too slow, and a radical or ionic reaction will not stop after one addition. Other possibilities for the conversion of the double bond 
are hydroboration, hydrosilation, free radical addition of thiols and reaction with chlorobenzoic acid.

The addition of maleic anhydride (MA) to PIB-U was studied by Tessier and Maréchal ${ }^{15,16}$. They used telechelic PIB as well as model compounds and analysed the products with ${ }^{1} \mathrm{H}$ n.m.r. It appeared that the MA reacted by means of an ene reaction with PIB-U.<smiles>[R]CC(=C)CC1CC(=O)OC1=O</smiles>

Ene reactions are also possible with azo compounds, which are more reactive than $\mathrm{MA}^{17}$ so that lower synthesis temperatures can be used. The use of this kind of reactant is not examined here.

Our aim was to study the synthesis of MA endcapped PIB, starting from the dichlorine terminated oligomers, as obtained by cationic polymerization.

\section{EXPERIMENTAL}

\section{Materials}

The synthesis of chlorine endcapped PIB is described elsewhere ${ }^{18}$. The $\mathrm{MA} \mathrm{TiCl}_{4}, \mathrm{AlCl}_{3}$ and the solvents were obtained from Merck.

\section{Analytical techniques}

I.r. spectroscopy. A Perkin-Elmer 1310 i.r. spectrophotometer and a Biorad 60 Fourier transform i.r. spectrophotometer were used for i.r. analyses of the PIB telechelics. The viscous telechelics were smeared as a thin film on one side of a $\mathrm{NaCl}$ plate.

${ }^{\prime} H$ n.m.r. End groups of the telechelics were studied with a Bruker $80 \mathrm{MHz}$ spectrometer. Solutions of $5-10 \%$ telechelic in $d$-chloroform were used. Trimethylsilane was used as an internal reference. The samples were scanned 100 times.

Osmometry. The molecular masses of the telechelics were determined with vapour pressure osmometry (v.p.o.). A range of four solutions was used varying from 5 to $40 \mathrm{~g} \mathrm{l}^{-1}$. The measurements were carried out at $36.6^{\circ} \mathrm{C}$ in chloroform. Benzil (1,2-diphenyl-1,2ethanedione) was used as a reference.

Titration. MA end groups were determined by titration with sodium methoxide ${ }^{19}(1 \mathrm{~mol}$ of sodium methoxide will react with $1 \mathrm{~mol}$ of anhydride). Thymol blue was used as an indicator.

\section{$M A$ functionalized $P I B$}

Addition of MA to the PIB telechelic was performed in two ways: one- and two-step methods were used.

One-step synthesis. A mixture of PIB-Cl (1.5 g, $\left.M_{\mathrm{n}}=1300\right)$ and MA $(0.6 \mathrm{~g})$ was heated to $190^{\circ} \mathrm{C}$ in the bulk in a nitrogen atmosphere for $12 h^{20}$. At this temperature, the viscosity of the telechelics was low $(<100 \mathrm{cP})$ so that magnetic stirrers were used for mixing.
The reaction was performed under a blanket of nitrogen gas. At the end, the reaction mass was cooled and dissolved in hexane. Unreacted MA and the black poly(maleic anhydride) are not soluble in hexane and were removed by filtration. The telechelic PIB was isolated by evaporating the hexane with a rotary evaporator and drying in a vacuum oven for $16 \mathrm{~h}$ at $80^{\circ} \mathrm{C}$. This final step removed the last traces of unreacted MA.

Two-step synthesis. The $\mathrm{PIB}-\mathrm{Cl}$ was first selectively dehydrochlorinated to PIB-U according to a method described in the literature ${ }^{21}$. The product was then converted to the anhydride terminated product (PIB-MA) in a second step using three different methods.

Bulk. Reaction of PIB-U with MA in the bulk was carried out by mixing PIB-U with MA and heating the mixture for $12 \mathrm{~h}$ at $190^{\circ} \mathrm{C}$. The reaction conditions and work-up were the same as described above.

Solvent. For the addition reaction in solution, PIB-U $(1.5 \mathrm{~g})$ and MA $(0.6 \mathrm{~g})$ were dissolved in benzyl alcohol $(25 \mathrm{ml})$. This mixture was reacted at $190^{\circ} \mathrm{C}$ for $12 \mathrm{~h}$. The insoluble fraction was then filtered off. The solvent was evaporated with a rotary evaporator and the product was dried in a vacuum oven at $140^{\circ} \mathrm{C}$ overnight. This also removed the last traces of MA.

Catalyst. A reaction vessel was filled with MA (0.6 g) and PIB-U (1.5 g) dissolved in methylene chloride (25 $\mathrm{ml})$. To this mixture was added $\mathrm{TiCl}_{4}(0.2 \mathrm{~mol})$ as a Lewis acid. This mixture was refluxed at $41^{\circ} \mathrm{C}$ for $16 \mathrm{~h}$. The methylene chloride was evaporated and the reaction products were dissolved in hexane. The catalysts and the unreacted MA could now be filtered off.

The same reaction was performed with $\mathrm{AlCl}_{3}$, which also acts as a Lewis acid under these conditions ${ }^{22}$.

\section{Addition of diaminoethane to PIB-MA}

The PIB-MA oligomer was mixed with excess diaminoethane. This was carried out by slowly adding a solution of PIB-MA $(15 \mathrm{~g})$ in toluene $(80 \mathrm{ml})$ to a refluxing solution of diaminoethane $(2.1 \mathrm{~g})$ in toluene $(60 \mathrm{ml})$. After $2 \mathrm{~h}$ at $111^{\circ} \mathrm{C}$, the toluene was vacuum evaporated. The oligomer was dissolved in hexane and the unreacted diamine was removed by washing the hexane solution with water and evaporating the hexane layer with a rotary evaporator.

The amic acid that was formed was transformed to an imide by a ring closing reaction at $110^{\circ} \mathrm{C}$ in a vacuum oven for $24 \mathrm{~h}$.

\section{RESULTS AND DISCUSSION}

\section{Dehydrochlorination}

I.r. analysis. PIB absorbs very weakly in the i.r. region. Large amounts of PIB could be used so that strong absorption bands of the end groups could be obtained. The characteristic bands of the PIB main chain and some end groups are given in Table 1. Figure I shows the i.r. spectrum before and after dehydrohalogenation.

The absorption of the $\mathrm{NaCl}$ support disc masks the absorption of the chlorine end group at $640 \mathrm{~cm}^{-1}$. For this reason, the spectrum in Figure Ia was made with a $\mathrm{NaCl}$ plate in the reference beam.

The unsaturated end groups of PIB-U absorb strongly 
at 890 and $1640 \mathrm{~cm}^{-1}$. The band at $890 \mathrm{~cm}^{-1}$ is particularly clear, even at low levels of unsaturation. Unsaturated end groups could be traced with i.r. at concentrations that were too small to detect with ${ }^{1} \mathrm{H}$ n.m.r.

N.m.r. analysis. PIB has a rather simple ${ }^{1} \mathrm{H}$ n.m.r. spectrum (Figure 2). The main chain of PIB shows two single peaks at 1.11 and $1.42 \mathrm{ppm}$. Also present are some small unknown peaks in the $1.0-2.3 \mathrm{ppm}$ range. The end groups and the bulk part of the chain have reasonably different peak positions so that the end groups of the telechelics can be examined and compared with the bulk (Figure 2A). The PIB-Cl shows four separate peaks (a-d). Two of these peaks $(a, b)$ originate from the main chain while the two smaller peaks (c, d) are produced by the end unit (Table 2).

The ${ }^{1} \mathrm{H}$ n.m.r. spectrum of PIB-U (Figure $2 b$ ) shows the disappearance of the methyl and methylene groups, adjacent to the chlorine (Figure $2 A, \mathrm{c}$, d), and the appearance of new peaks from the unsaturated end group at $4.85,4.65,1.78$ and $2.00 \mathrm{ppm}$ (Figure $2 B$, e-h). No peak is visible at $5.15 \mathrm{ppm}$, as would be the case if there was a 2,3-double bond (endo). From the spectrum it can therefore be concluded that the double bond formed is exclusively a 1,2-bond (exo).

\section{$M A$ addition}

I.r. analysis. For the PIB-MA oligomer, two strong anhydride i.r. bands at 1790 and $1855 \mathrm{~cm}^{-1}$ and a minor

Table 1 Main i.r. bands of PIB and its end groups with their assignments

\begin{tabular}{|c|c|c|c|}
\hline & $\begin{array}{l}\text { Wavelength } \\
\left(\mathrm{cm}^{-1}\right)\end{array}$ & Intensity ${ }^{a}$ & Origin \\
\hline PIB main chain & $\begin{array}{r}2980 \\
2950 \\
2890 \\
2720 \\
1465 \\
1385 \\
1360 \\
1225 \\
1160 \\
950 \\
920\end{array}$ & $\begin{array}{l}\mathrm{s} \\
\mathrm{s} \\
\mathrm{s} \\
\mathrm{w} \\
\mathrm{s} \\
\mathrm{s} \\
\mathrm{s} \\
\mathrm{s} \\
\mathrm{m} \\
\mathrm{m} \\
\mathrm{m}\end{array}$ & $\begin{array}{l}\mathrm{CH} \text { stretch } \\
\mathrm{CH} \text { stretch } \\
\mathrm{CH} \text { stretch } \\
\mathrm{CH} \text { stretch } \\
\mathrm{CH} \text { bend } \\
\mathrm{CH}_{3} \text { swing } \\
\mathrm{CH}_{3} \text { swing } \\
\mathrm{C}-\mathrm{H} \text { bend in }-\mathrm{CH}_{2}-\end{array}$ \\
\hline Chlorine group & 640 & vw & $\mathrm{Cl}$ \\
\hline $\begin{array}{l}\text { Unsaturated } \\
\text { group }\end{array}$ & $\begin{array}{r}3080 \\
1780 \\
1640 \\
890\end{array}$ & $\begin{array}{l}\mathrm{m} \\
\mathrm{w} \\
\mathrm{m} \\
\mathrm{s}\end{array}$ & $\begin{array}{l}=\mathrm{CH}_{2} \text { asym. stretch } \\
=\mathrm{CH}_{2} \text { wag } \\
\mathrm{C}=\mathrm{C} \text { stretch } \\
=\mathrm{CH}_{2} \text { wag }\end{array}$ \\
\hline $\begin{array}{l}\text { Anhydride } \\
\text { group }\end{array}$ & $\begin{array}{r}1855 \\
1780 \\
715\end{array}$ & $\begin{array}{l}\text { s } \\
\text { vs } \\
\text { m }\end{array}$ & $\begin{array}{l}C=O \text { sym. stretch } \\
C=O \text { asym. stretch }\end{array}$ \\
\hline
\end{tabular}

${ }^{a}$ vs, very strong; s, strong; m, medium; w, weak; vw, very weak

Table 2. ${ }^{1} \mathrm{H}$ n.m.r. peak positions from Figure 2

\begin{tabular}{lll}
\hline $\mathrm{H}$ & Chemical shift (ppm) & \\
\hline $\mathrm{a}$ & 1.11 & Singlet \\
$\mathrm{b}$ & 1.42 & Singlet \\
$\mathrm{c}$ & 1.68 & Singlet \\
$\mathrm{d}$ & 1.96 & Singlet \\
$\mathrm{e}$ & 1.78 & Singlet \\
$\mathrm{f}$ & 1.99 & Singlet \\
$\mathrm{g}$ & 4.65 & Singlet/possibly doublets \\
$\mathrm{h}$ & 4.82 & Singlet/possible doublets \\
\hline
\end{tabular}

band at $715 \mathrm{~cm}^{-1}$ were found (Table 1, Figure 1C). Although the anhydride was present only in the end groups, it had an absorbance of the same order of magnitude as the strong bands in the PIB main chain.

The unsaturated band seen at $890 \mathrm{~cm}^{-1}$ in the case of PIB-U, had disappeared completely in the i.r. spectrum of PIB-MA. According to the reaction mechanism, a new double bond was formed but this could not be observed with i.r. It is possible that the band is shifted $30 \mathrm{~cm}^{-1}$ and is obscured behind the adjacent $\mathrm{C}-\mathrm{C}$ stretching band. That this group is present can be seen in the n.m.r. spectrum.

On the other hand, the absorption of the anhydride asymmetric $\mathrm{C}=\mathrm{O}$ stretching band at $1790 \mathrm{~cm}^{-1}$ is very strong. For PIB-MA samples with known (titrated) MA concentration, the i.r. transmission ratio was determined by comparing the logarithmic height of the anhydride band at $1790 \mathrm{~cm}^{-1}$ with the logarithmic height of the PIB band at $1390 \mathrm{~cm}^{-1}$ (Figure 3). As the samples had only a low MA content, some high MA concentrations were made by mixing MA with PIB. The i.r. transmissions of these mixtures in tetrahydrofuran (THF) are also presented in Figure 3. Through data derived with both methods, one line can be drawn. The slope of this line can be represented by:

$$
\frac{[\mathrm{MA}]}{[\mathrm{IB}]}=0.024 \times \frac{\text { peak height at } 1785 \mathrm{~cm}^{-1}}{\text { peak height at } 1390 \mathrm{~cm}^{-1}}
$$

This relation was used for a rough analysis of the anhydride content of other samples.

N.m.r. analysis. The peak assignments of Tessier and Maréchal $^{16,23,24}$ were followed. The presence of the anhydride groups is difficult to observe by ${ }^{1} \mathbf{H}$ n.m.r., because the two protons give several small peaks distributed over a broad range that lies around $2.5 \mathrm{ppm}$. (See, for example, the comparable spectra of octadecylsuccinic anhydride or 1-docosenyl succinic anhydride ${ }^{25}$.) Only the newly formed unsaturated group gives one clearly visible peak at $4.91 \mathrm{ppm}$. The peaks from the original unsaturated bond have disappeared. The n.m.r. spectrum of PIB-Cl and PIB-U compares very well with those of Tessier and Maréchal.

Conversions of monofunctional PIB. The addition of MA to PIB was measured by the absorption ratio of two characteristic bands in the i.r. spectrum. The fraction of MA groups can be correlated with the number-average molecular weight $\left(M_{n}\right)$ in order to determine the functionality. The data presented in Table 3 were derived from monofunctional oligomers from the same polymer batch, with a $M_{\mathrm{n}}$ of $1800 \mathrm{~g} \mathrm{~mol}^{-1}$. Using one batch eliminates the differences between the results due to errors in the determination of $M_{\mathrm{n}}$ of these monofunctional oligomers. Reaction of the MA directly with the PIB-Cl at high temperatures (no. 1) gave low MA addition. Synthesis in two separate steps with the bulk method (no. 2) gave a high conversion. A high temperature reaction carried out in benzyl alcohol as solvent (no. 3) gave lower conversions. A low temperature reaction with $\mathrm{TiCl}_{4}$ as catalyst in refluxing $\mathrm{CH}_{2} \mathrm{Cl}_{2}$ gave good results (no. 4) but poor results if $\mathrm{AlCl}_{3}$ was used as catalyst (no. 5).

The high temperature reaction with the PIB-U is the most effective. This conversion method was therefore used in our further synthesis with difunctional oligomers. The conversion on the whole is low but probably has a 


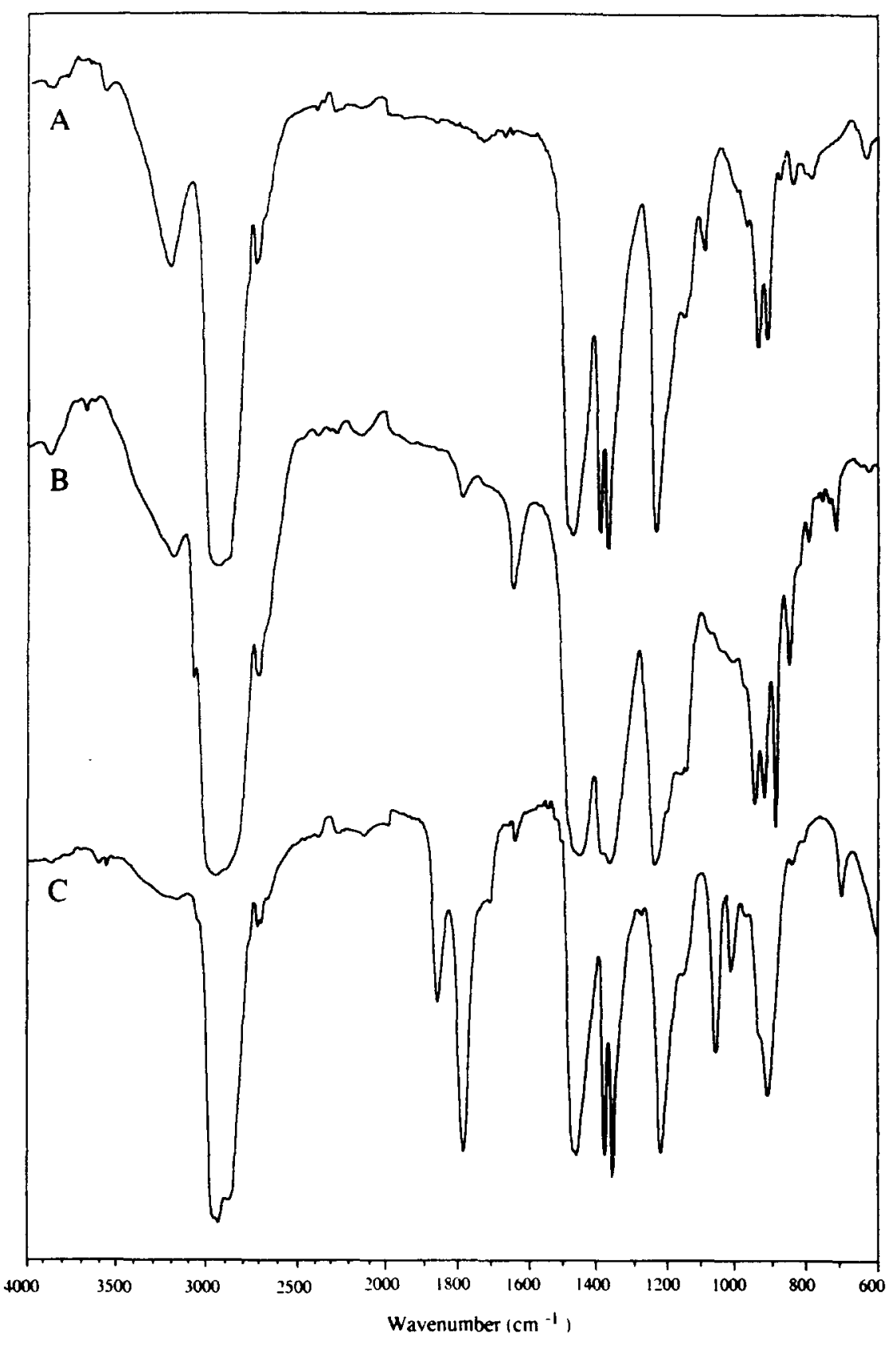

Figure 1 I.r. spectra of telechelic PIB: (A) chlorine terminated PIB; (B) the same telechelic after dehydrochlorination; (C) telechelic after MA addition

Table 3 Maleic anhydride addition as a function of reaction conditions. A monofunctional PIB $\left(M_{\mathrm{n}}=1800 \mathrm{~g}\right.$ mol $\left.{ }^{-1}\right)$ was used

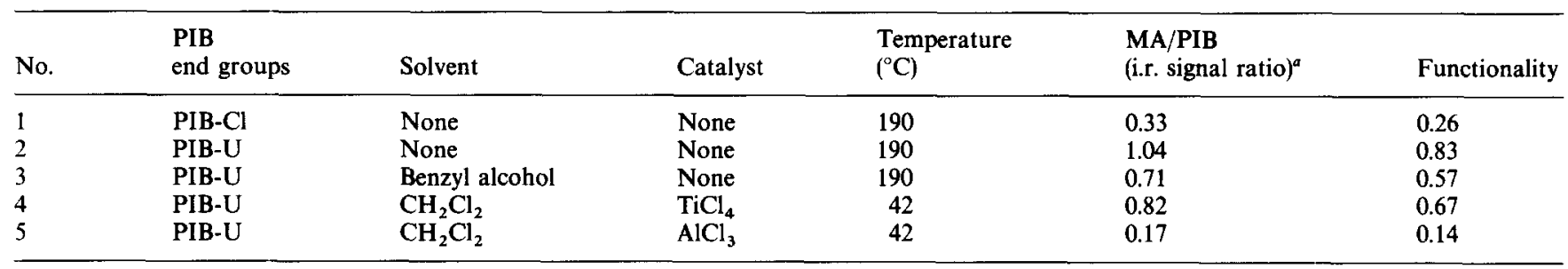

${ }^{a}$ Bands at 1785 and $1390 \mathrm{~cm}^{-1}$

systematic error caused by a poor molecular weight determination of this particular polymer batch.

Difunctional PIB. For the reasons described above, the synthesis of functional PIB-U was performed in the bulk. The data of MA addition to difunctional oligomer are given in Table 4. Functionalities above 2 (no. 8 and no. 9) are very unlikely and are probably due to an inaccuracy of the molecular weight determination. The osmometric data on which the functionality is based had a precision of $\pm 10 \%$. All oligomers used in our further investigations had a calculated functionality above $90 \%$.

The telechelic PIB-MA was colourless only in some cases. In most cases, the polymer was yellowish to light 


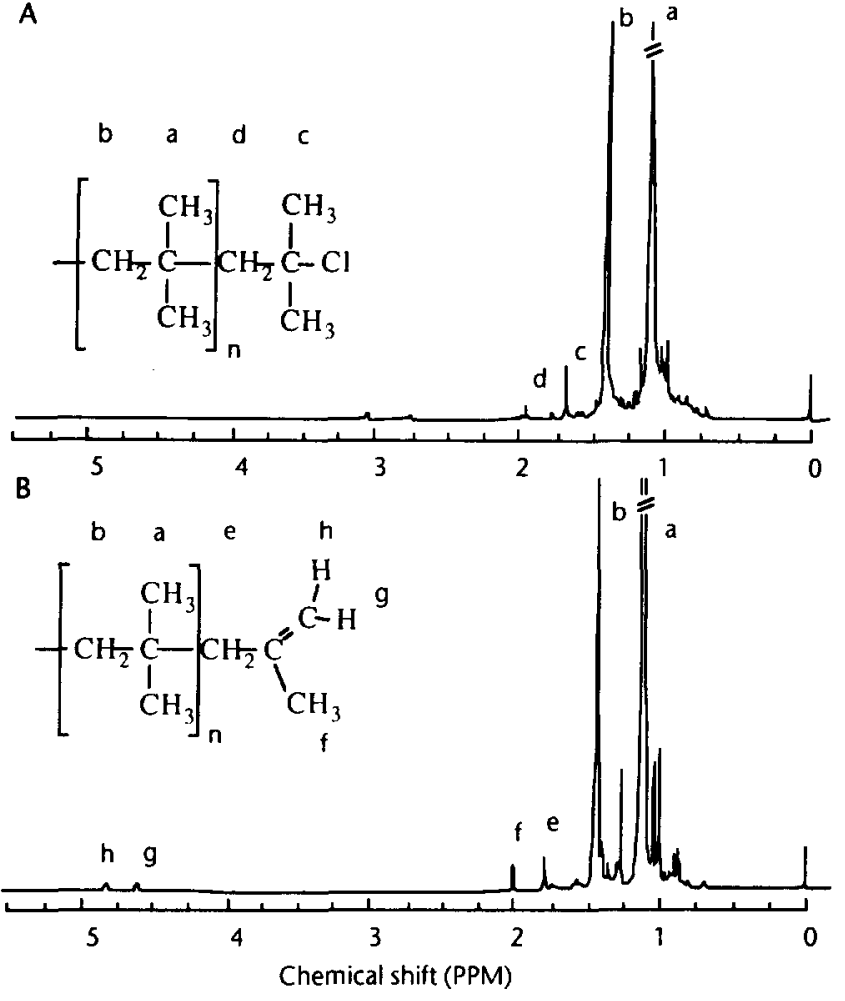

Figure $2{ }^{1} \mathrm{H}$ n.m.r. spectra of a $\mathrm{PIB}-\mathrm{Cl}$ telechelic (A) and the same telechelic after dehydrochlorination to PIB-U (B)

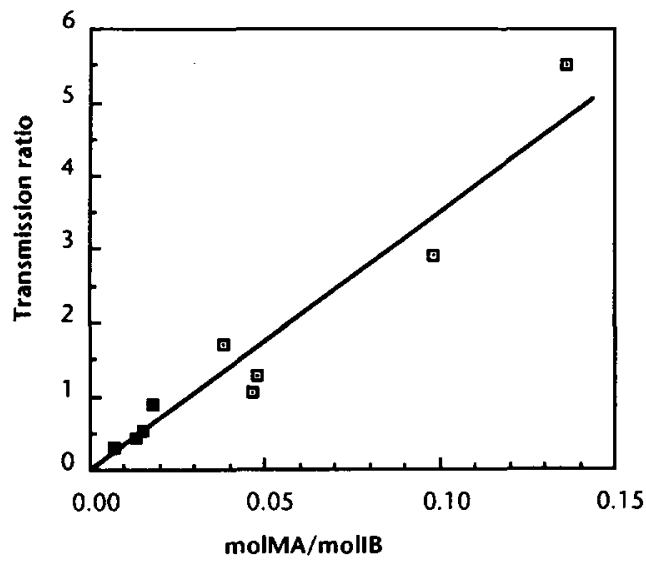

Figure 3 Calibration of PIB/MA transmission of the i.r. bands at 1785 and $1390 \mathrm{~cm}^{-1}$ as a function of the molar ratio: $(\square)$ titrated data; $(\square)$ mixtures of MA with PIB

Table 4 Maleic anhydride addition at PIB-U

\begin{tabular}{llll}
\hline No. & $\begin{array}{l}M_{\mathrm{n}} \text { (v.p.o.) } \\
\left(\mathrm{g} \mathrm{mol}^{-1}\right)\end{array}$ & $\begin{array}{l}\text { MA } \\
\left(\mathrm{mmol} \mathrm{g}^{-1}\right)\end{array}$ & Functionality $^{a}$ \\
\hline 6 & 2310 & 0.85 & 2.0 \\
7 & 2310 & 0.80 & 1.8 \\
8 & 1930 & 1.18 & 2.3 \\
9 & 1930 & 1.08 & 2.1 \\
\hline
\end{tabular}

${ }^{a}$ Data contain an error due to error in $M_{\mathrm{n}}$

brown. This colouring is thought to originate from poly(maleic anhydride).

\section{Diaminoethane addition}

The reaction of the PIB-MA with diaminoethane was examined in order to evaluate the possibility of synthesizing endcapped PIB. The anhydride can react with amine groups with the formation of an amic acid bond that can be converted in a second heating step to a very stable imide bond. I.r. spectroscopy showed the complete disappearance of the anhydride $\left(1800 \mathrm{~cm}^{-1}\right)$, and the formation of an amide bond (1550 and $\left.1635 \mathrm{~cm}^{-1}\right)$. After the first step, only a small amount of imide $\left(1705 \mathrm{~cm}^{-1}\right)$ was found. I.r. spectroscopy showed that the amic acid bond was converted to the imide bond in the second step.

\section{CONCLUSIONS}

Synthesis of anhydride terminated PIB telechelics (PIBMA) in one step by heating a chlorine terminated PIB in the presence of MA gives only a low conversion. In this bulk process an unsaturation at the $\beta$-position (endo) was formed, which reacts slowly in the successive ene reaction.

The synthesis of PIB-MA was carried out in two steps, by first selectively removing $\mathrm{HCl}$ to form an $\alpha$ unsaturation (exo). Maleic anhydride was, in the second step, successfully added to this double bond as shown by i.r. and n.m.r. Conversion to amine end groups is possible by adding diaminoethane to PIB-MA.

\section{ACKNOWLEDGEMENT}

This work is part of the research programme of the University of Twente and was financially supported by the Netherlands Innovative Research Programme for Polymers (IOP).

\section{REFERENCES}

1 Sawamoto, M., Eniki, T. and Higashimura, T. Polym. Bull. 1987, 18, 117

2 Faust, R. and Kennedy, J. P. J. Polym. Sci., Polym. Chem. Edn 1987, 25, 1847

3 Ivan, B. and Kennedy, J. P. J. Polym. Sci., Polym. Chem. Edn. $1990,28,89$

4 Mishra, M. K., Sar-Mishra, B. and Kennedy, J. P. Polym. Bull. $1986,16,47$

5 Kennedy, J. P. and Ivan, B. 'Designed Polymers by Carbocationic Macromolecular Engineering', Hansen, Munich, 1991 Kennedy, J. P. Rubber Chem. Technol. 1983, 56, 639 Kennedy, J. P. Makromol. Chem. Suppl. 1984, 7, 171 Hoffman, H. M. R. Angew. Chem. 1969, 81, 597 Solomons, T. W. G. 'Organic Chemistry', 4th Edn, John Wiley \& Sons, New York, 1988

10 Kennedy, J. P., Chang, V. S. C., Smith, R. A. and Ivan, B. Polym. Bull. 1979, 1, 575

11 Mishra, M. K., Sar-Mishra, B. and Kennedy, J. P. Polym. Bull. $1985,13,435$

Kennedy, J. P. Rubber Chem. Technol. 1983, 56, 639

Clocker, E. I. US Pat. 21888821940

Hill, R. and Barger, H. J. Org. Chem. 1965, 30, 2558

Tessier, M. and Maréchal, E. Eur. Polym. J. 1984, 20, 281

Tessier, M. and Maréchal, E. Eur. Polym. J. 1990, 26, 499 Butler, G. B. Ind. Eng. Chem., Prod. Res. Dev. 1980, 19, 512

18 Walch, E. and Gaymans, R. J. Polymer 1993, 34, 412

19 Hyvis polybutenes, Technical Note HCR/1, British Petroleum, 1987

Kyrides, L. P. US Pat. 23604261945

21 Kennedy, J. P., Chang, V. S. C., Smith, R. A. and Iván, B. Polym Bull. 1979, 1, 575

Snider, B. B. Acc. Chem. Res. 1980, 13, 426

Tessier, M. and Maréchal, E. Polym. Bull. 1983, 10, 152

Tessier, M. and Maréchal, E. Eur. Polym. J. 1986, 22, 889

Sadtler Standard Spectra, Sadtler Research Laboratories, 1980 